\title{
Editors' Overview on this special issue: "The Psycholinguistics of Writing"
}

In the last thirty years, research on the psychology of language has broached a number of practical problems relating to the comprehension of speech, print, sign, and several other codes. Parallel work on linguistic expression, with one significant exception, has moved forward in these areas as well. The exception, of course has been writing. In the last few years, as never before, there has been a surge of interest in writing. Some recent studies have dealt with the acquisition of expressive graphic systems and the teaching of writing skills, others have focused on the ways in which linguistic structure varies in speaking and writing, the processes by which thought is conveyed by print, and the impairment of writing processes in cases of neurological insult and dementia.

This special issue, "Psycholinguistics of Writing," collects research reports that deal with the development of writing, the improvement of writing skills in normal and in disabled populations, and the mechanisms underlying writing dysfunction. Developmental issues addressed include children's discovery of the graphic system and increasing differentiation of writing from drawing (Tolchinsky-Landsmann and Levin), and the decreasing reliance on phonetic representation in spelling (Treiman). Two studies report on the use of microcomputers to improve children's writing skills, one with ASL speakers (Prinz and Nelson) and one with junior high school students who receive computer-prompts to reread and revise (Daiute and Kruidenier). A study of patients with right-brain damage examines anomalies in their writing as compared to reading and drawing (Lebrun), and a neuropsychological mechanism and associated anatomic substrate for writing is proposed based on an analysis of agraphia as related to alexia and aphasia (Roeltgen and Heilman). Finally, the issue contains reviews of four major volumes on writing and writing development. The issue presents an invaluable resource of up-to-date, research-based approaches to understanding the psycholinguistics of writing by studying its development, the factors that relate to its improvement, and its breakdown. 